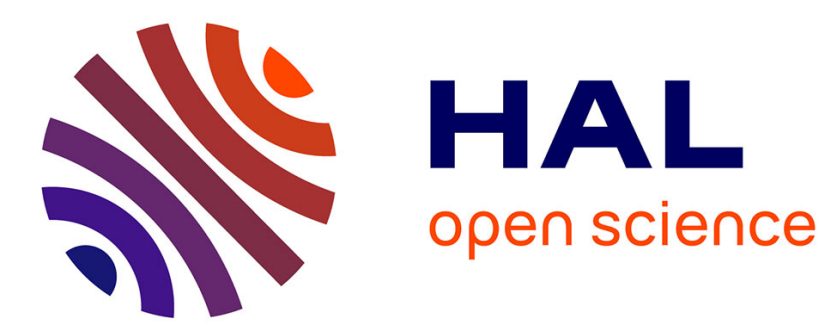

\title{
A computational strategy for the analysis of damage in composite pipes
}

\author{
Emmanuel Baranger, O. Allix, L. Blanchard, Lmt Cachan
}

\section{To cite this version:}

Emmanuel Baranger, O. Allix, L. Blanchard, Lmt Cachan. A computational strategy for the analysis of damage in composite pipes. Composites Science and Technology, 2009, 69 (1), pp.88. 10.1016/j.compscitech.2007.10.050 . hal-00575235

\section{HAL Id: hal-00575235 \\ https://hal.science/hal-00575235}

Submitted on 10 Mar 2011

HAL is a multi-disciplinary open access archive for the deposit and dissemination of scientific research documents, whether they are published or not. The documents may come from teaching and research institutions in France or abroad, or from public or private research centers.
L'archive ouverte pluridisciplinaire HAL, est destinée au dépôt et à la diffusion de documents scientifiques de niveau recherche, publiés ou non, émanant des établissements d'enseignement et de recherche français ou étrangers, des laboratoires publics ou privés. 


\section{Accepted Manuscript}

A computational strategy for the analysis of damage in composite pipes

E. Baranger, O. Allix, L. Blanchard, Lmt Cachan

PII:

S0266-3538(07)00442-3

DOI:

10.1016/j.compscitech.2007.10.050

Reference:

CSTE 3891

To appear in:

Composites Science and Technology

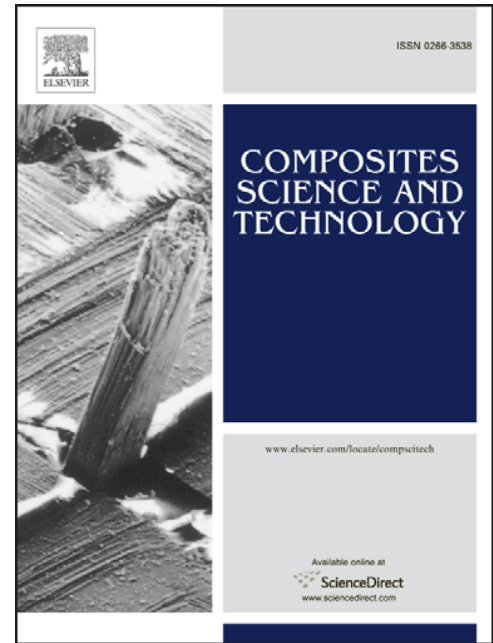

Received Date:

14 May 2007

Accepted Date:

11 October 2007

Please cite this article as: Baranger, E., Allix, O., Blanchard, L., Cachan, L., A computational strategy for the analysis of damage in composite pipes, Composites Science and Technology (2007), doi: 10.1016/j.compscitech. 2007.10.050

This is a PDF file of an unedited manuscript that has been accepted for publication. As a service to our customers we are providing this early version of the manuscript. The manuscript will undergo copyediting, typesetting, and review of the resulting proof before it is published in its final form. Please note that during the production process errors may be discovered which could affect the content, and all legal disclaimers that apply to the journal pertain. 


\title{
A COMPUTATIONAL STRATEGY FOR THE ANALYSIS OF DAMAGE IN COMPOSITE PIPES
}

\author{
E. Baranger*, O. Allix* and L. Blanchard** \\ *LMT Cachan \\ 61 avenue du Président Wilson, 94235 Cachan Cedex, France \\ e-mail : allix@1mt.ens-cachan.fr \\ **Alcatel Alenia Space \\ 100 boulevard du Midi, 06156 Cannes La Bocca cedex, France \\ e-mail : Laurent.Blanchard@alcatelaleniaspace.com
}

\begin{abstract}
The aim of this work is the determination of the influence of manufacturing defects on the behavior of composite pipes. We present an efficient numerical tool to solve this problem which relies on a strategy dedicated to pipes. Since most of the harmful manufacturing defects are located at the ends of the pipes, a complete $3 \mathrm{D}$ calculation is not necessary and only the ends are analyzed finely. The center of the pipe is modeled as an elastic beam and the ends as 3D nonlinear zones. The connection between the beam model and the end models is carried out using the Saint-Venant solution of the elastic problem, so that no spurious effects occur near the connection zone. This Saint-Venant solution is built from the exact beam theory. The nonlinear end problem is solved by a traditional method (secant Newton), but each elastic stage benefits from a particular treatment. In order for each 3D elastic problem to be solved
\end{abstract}


efficiently, it is uncoupled into a set of dedicated 2D problems using a Fourier series expansion. Transfer between the 2D and 3D states is achieved using fast Fourier transform.

KEYWORDS: DELAMINATION, PIPE, DEFECT, DAMAGE, COMPOSITE. 


\section{INTRODUCTION}

During the manufacturing of composite pipes, some defects - such as delamination, fiber breakage or lack of matrix - appear. Today, these defects are not taken into account in pipe design. Therefore, one faces the problem of deciding whether a pipe can be used or must be rejected. Our objective is to provide the engineers of Alcatel Alenia Space with a numerical decision tool capable of predicting the behavior of RTM composite pipes in the presence of defects. The analysis of a full 3D nonlinear pipe model would be too expensive. Since the major degradations are localized mainly at the ends of the pipe, the calculation can be simplified and an elastic beam model used to generate the inner solution. In fact, it provides the Saint-Venant solution of the problem which will be used in a subsequent stage to generate the boundary conditions to be applied to the $3 \mathrm{D}$ model of the pipe's end. The nonlinear calculation is performed on this end zone alone and can be carried out using a secant Newton algorithm. However, the different elastic resolutions associated with this algorithm remain very expensive. For this reason, this end problem is uncoupled into a set of 2D problems using a dedicated Fourier series expansion. This technique, which is restricted to pipes whose behavior in the hoop direction is constant, can be extended to more general cases using a preconditioned conjugate gradient technique.

First, we will present the elastic calculation (i.e. the model linking problem and the Fourier expansion). Next, we will develop the nonlinear calculation. Finally, the strategy will be illustrated using the example presented in the following section. 


\section{DESCRIPTION OF THE PROBLEM}

The pipes being considered in this paper are composed of carbon fabric plies and an epoxy matrix (G802/914). These plies are wound with an angle denoted $\alpha$, as indicated on Figure 1. The data relative to this material are given in (Hochard et al., 01) and the stacking sequence is [22.5/-22.5/0/-22.5/22.5]. The pipe (diameter: $36 \mathrm{~mm}$ ) is clamped through a titanium sleeve (overlapping length: $20 \mathrm{~mm}$ ) and is solicited in bending (force: $300 \mathrm{~N}$ at $144 \mathrm{~mm}$ from the built-in end).

\section{THE ELASTIC CALCULATION}

\section{Resolution of the problem of connecting the 1D and 3D models}

A beam theory is used to calculate the elastic solution in the center of the pipe. Then, the boundary conditions to be applied to the $3 \mathrm{D}$ models of the ends of the pipe are built from this beam solution; however, one must be cautious that this link do no generate spurious damage near the linking zone.

In order to avoid localized effects in the linking region, the information contained in this link must be the Saint-Venant solution of the elastic problem (i.e. the long-wave part of the solution). Therefore, the beam theory being used must contain this Saint-Venant solution. This is not the case of classical theories, such as Euler-Bernoulli's. Instead, the exact beam theory developed by (Ladevèze et al., 98) can be used. 
Contrary to classical beam theories which are based on mixed assumptions concerning stresses and displacements, the exact beam theory does not rely on such assumptions. It is based on the Saint-Venant principle viewed as the definition of equivalent classes of boundary conditions leading to localized stresses and displacements. Thus, a structure loaded with two types of boundary conditions having the same generalized stresses and displacements leads to the same Saint-Venant solution.

The beam problem to be solved is: find the generalized stresses and displacements: $(\tilde{T}, \tilde{M})$ and $(\tilde{u}, \tilde{\omega})$ which verify:

- the equilibrium equations: $\begin{aligned} & \frac{d \tilde{T}}{d z}+f_{d}(z)=0 \\ & \frac{d \tilde{M}}{d z}+\vec{e}_{z} \wedge \tilde{T}=0\end{aligned}$

- the constitutive relation: $\begin{aligned} & \tilde{\gamma} \\ & \tilde{\chi}\end{aligned}=\Lambda \begin{aligned} & \tilde{M} \\ & \tilde{T}\end{aligned}+\begin{aligned} & z_{d} \\ & Z_{d}\end{aligned}$ with $\begin{gathered}\tilde{\gamma}=\tilde{u}_{z,}+\vec{e}_{z} \wedge \tilde{\omega} \\ \tilde{\chi}=\tilde{\omega}_{z,}\end{gathered}$

The Saint-Venant solution $\left(U_{s v}, \sigma_{s v}\right)$ can be written in the form:

$$
\begin{gathered}
U_{s v}=\tilde{u}+\tilde{\omega} \wedge \overrightarrow{m M}+A \tilde{T}+B \tilde{M}+z_{d} \\
\sigma_{s v} \vec{e}_{z}=A^{\circ} \tilde{T}+B^{\circ} \tilde{M}+Z_{d}
\end{gathered}
$$

The use of this beam model requires the identification of the operators $A, B, z_{d}, A^{\circ}, B^{\circ}, Z_{d}$. In order to do that, different techniques can be used (Sanchez et al., 99) (El Fatmi et al., 
02). In our case, the Saint-Venant solution is obtained for 6 elementary problems (tension, torsion, pure bending, simple bending) by solving an edge effect problem and extracting the inner part of the solution.

Figure 2 represents the longitudinal evolution of the radial stress at different interfaces between plies and for a zero polar angle. No spurious effects occur in the linking zone (the rightmost part of the figure). Because of the stress concentration at the end of the sleeve, delamination would certainly initiate in this zone.

\section{Resolution technique for the elastic end problem}

A finite element method adapted to cylindrical composite pipes is used to solve the 3D end problem efficiently. This technique consists in replacing an expensive 3D problem by a set of $2 \mathrm{D}$ problems each defined along a strip. Indeed, in $3 \mathrm{D}$, the $2 \pi$ periodicity of the fields introduces a strong coupling among the degrees of freedom (causing the stiffness matrix to have a large bandwidth). To get around this problem, the loading and the unknowns are expanded into Fourier series which are denoted, for vectors and seconddegree symmetric tensors quantities respectively:

$$
\begin{gathered}
U=P_{0} U_{0}+{ }_{n=1}^{N} P_{n} U_{n}+P_{-n} U_{-n} \\
\mathcal{E}=R_{0} \varepsilon_{0}+{ }_{n=1}^{N} R_{n} \varepsilon_{n}, R_{-n} \varepsilon_{-n}
\end{gathered}
$$


Introducing these expressions into the principle of virtual work, one gets:

$$
\begin{aligned}
& P_{i}^{*}={ }_{\text {Strip }} \varepsilon_{0} 2 \pi K \varepsilon_{0}^{*} d S+{ }_{\text {Strip Interface }}\left[U_{0}\right]^{T} 2 \pi k\left[U_{0}\right]^{*} d s
\end{aligned}
$$

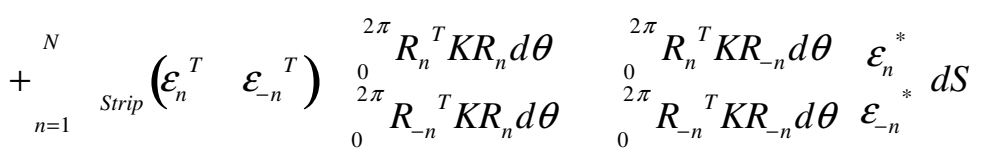

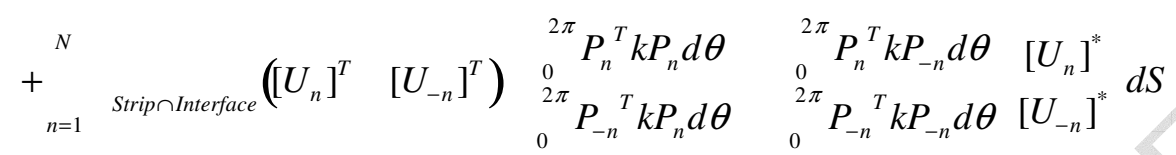

This expansion enables us to uncouple the 3D problem into a set of $2 \mathrm{D}$ problems with twice as many unknowns per node for the harmonic problems (coupling between the $+n$ en $-n$ modes). The transfer from the $3 \mathrm{D}$ problem to the set of $2 \mathrm{D}$ problems is achieved using FFT and the inverse transformation (Brigham, 88).

A necessary condition for uncoupling is for the behavior (expressed in the cylindrical basis) to be constant in the hoop direction. The healthy pipe verifies this condition, but the damaged pipe does not. Then, the preconditioned conjugate gradient method is used to solve the $3 \mathrm{D}$ end problem. The preconditioner is chosen such that the uncoupling assumption is verified. In practice, the healthy pipe behavior is used.

\section{RESOLUTION OF THE NONLINEAR 3D END PROBLEM}

\section{The material model}

In order to predict the evolution of the degradations in the pipe, a damage mesomodel based on the work of (Ladevèze 86) is used. The structure is divided into a stacking of 
plies (Hochard et al., 01) (Ladevèze et al., 92) and interfaces (Allix et al., 95-98). These two entities (plies and interfaces) are independent of the stacking sequence and are continuous media in the framework of damage mechanics. The ply entity provides the description of transverse cracking and fiber breakage in the directions of the fabric while the interfaces enable one to describe delamination. In this model, damage (denoted $d_{i}$ ) is controlled by the associated thermodynamic force (denoted $\mathrm{Y}_{\mathrm{di}}$ )

$$
Y_{d_{i}}=\frac{\partial E_{d}}{\partial d_{i}}
$$

For example, for fabric plies and for a plane stress state, the strain energy can be written as:

$$
2 E_{d}^{P S}=\frac{\left\langle\sigma_{11}\right\rangle_{+}{ }^{2}}{E_{1}^{0}\left(1-d_{1}\right)}+\frac{\left\langle-\sigma_{11}\right\rangle_{+}{ }^{2}}{E_{1}^{0}}-2 \frac{v_{12}^{0}}{E_{1}^{0}} \sigma_{11} \sigma_{22}+\frac{\left\langle\sigma_{22}\right\rangle_{+}^{2}}{E_{2}^{0}\left(1-d_{2}\right)}+\frac{\left\langle-\sigma_{22}\right\rangle_{+}{ }^{2}}{E_{2}^{0}}+\frac{\sigma_{12}{ }^{2}}{G_{12}^{0}\left(1-d_{12}\right)} \text { Then, the }
$$

constitutive relations for the plies are:

$$
\begin{gathered}
d_{12}=\frac{\sqrt{Y}-\sqrt{Y_{0}}}{\sqrt{Y_{c}}-\sqrt{Y_{0}}} \\
\forall i \in[1,2] \text { if } Y_{d_{i}}<Y_{d_{f}} \text { then } d_{i}=0 \text { else } 1
\end{gathered}
$$

with $Y=\alpha_{1} Y_{d_{1}}+\alpha_{2} Y_{d_{2}}+Y_{d_{12}}$ and $Y(t)=\sup _{\tau \leq t} Y(\tau)$

In addition, a plasticity model with kinematic strain hardening is used to model possible friction in the cracks. Coupling between plasticity and damage is achieved by the introduction of effective stress and strain (Ladevèze, 94). 


\section{Resolution algorithm for the nonlinear problem}

The nonlinear problem is solved through a secant Newton algorithm. Each linear step is solved with a preconditioned conjugate gradient. The problem associated with the preconditioner is expanded into a Fourier series as presented before. The behavior is numerically integrated using an Ortiz and Simo algorithm (Ortiz et al., 86).

Remark: during the elastic calculations, the modes are coupled in pairs. The global construction of the solution is carried out when the behavior and the corresponding FFT are actualized.

In the future, an arc-length algorithm (Alfano et al., 01-03) will be implemented to pass critical points present on the structural behavior.

\section{NUMERICAL RESULTS}

Figure 3 shows the evolution of the stress in the direction of the warp fibers. There is a stress concentration at the end of the overlapping zone between the sleeve and the composite pipe. Fiber breakage would certainly occur there. Figure 4 shows the evolution of the damage variable $\mathrm{d}_{12}$, which goes up to $6 \%$ at the end of the sleeve. Moreover, on Figure 2, the pipe can be divided into two zones: the inner zone, where the stress is zero, and the end zone with the sleeve, where there is a local effect. Thus, we can assume that a defect present in the inner zone would have no effect because it would not modify the 
stress field. For a defect present at the end of the pipe under the sleeve, a more detailed analysis must be conducted.

\section{CONCLUSION}

We proposed a dedicated computational strategy for composite pipes whose purpose is to deal with the influence of defects on delamination efficiently. The pipe is divided into two zones: the inner zone, modeled using an elastic beam theory, and the end zone, where major degradation takes place, for which a nonlinear 3D model is used.

First, the beam problem is solved and the boundary conditions to be applied to the refined model of the end zone are determined. In order to do that, exact beam theory is used to generate the Saint-Venant solution of the inner problem. Then, the refined end model is solved. Then, a second stage consists in uncoupling each elastic 3D problem into a set of 2D problems using of a Fourier series expansion. Finally, a secant Newton algorithm is used to solve the nonlinear end problem.

The next step of this development will concentrate on the introduction of defects, such as delamination, and on a technique to take them into account in the calculation.

This work was carried out as part of the AMERICO project (Multiscale Analyses: Innovative Research for CFRPs) directed by ONERA (the French Aeronautics and Space Research Center) and funded by DGA/STTC (the French Ministry of Defense), whose support is gratefully acknowledged. 


\section{BIBLIOGRAPHY}

Ladevèze P. et Simmonds J., 1998, "New concepts for linear beam theory with arbitrary geometry and loading", Eur. J. Mech. Solids, v. 17 , no. 3, pp. 377-402.

Sanchez P., Ladevèze P., Simmonds J., 1999, "Illustration de la théorie exacte des poutres", 14ème congrès français de mécanique ,Toulouse.

El Fatmi R., Zenzri H., 2002, "On the structural behavior and the Saint-Venant solution in the exact beam theory. Application to laminated composite beams.", Comput. Struct. , v. 80, pp. $1441-1456$.

Brigham E. O., 1988, The Fast Fourier Transform and Applications, Englewood Cliffs, Prentice Hall.

Hochard C., Aubourg P.A., Charles J.P., 2001, "Modelling of the mechanical behavior of woven-fabric CFRP laminates up to failure.", Compos. Sci. Technol., v. 61, pp. 221-230. Ladevèze P., Sur la mecanique de l'endommagement des composites. Comptes rendus des JNC 5, eds C. Bathias \& D. Menkes. Pluralis Pub., Paris, 1986, 667-83. 18.

Ladevèze P., 1992, "A damage computational method for composite structures", Comput. Struct., v. 44, no.1/2, pp. 79-87.

Allix O., Ladevèze P., Corigliano A., 1995, "Damage analysis of interlaminar fracture specimens", Compos. Struct. v. 31, no. 1, pp. 61-74.

Allix O., Lévêque D., Perret L., 1998, "Identification and forecast of delamination in composite laminates by an interlaminar interface model", Compos. Sci. Technol., v. 58, no. 5 , pp. 671-678. 
Ladevèze P., 1994, "Inelastic strains and damage", in T.R. ed., Damage Mechanics of composite materials, Elsevier, pp. 117-132.

Ortiz M., Simo J. C., 1986, "An analysis of a new class of integration algorithms for elastoplastic constitutive relations", Int. J. Numer. Meth. Engng., v. 23, pp. 353-366.

Alfano G., Crisfield M. A., 2001, "Finite element interface models for delamination analysis of laminated composites : mechanical and computational issues", Int. J. Numer. Meth. Engng., v. 50, pp. 1701-1736.

Alfano G., Crisfield M. A., 2003, "Solution strategies for the delamination analysis based on a combination of loacl-control arc-length and line searches", Int. J. Numer. Meth. Engng., v. 58, pp. 999-1048. 


\section{FIGURE CAPTION}

Figure 1: Geometry of the pipe

Figure 2: Radial stress evolution in the interfaces

Figure 3: Local stress in the direction of the warp fibers of the plies (MPa)

Figure $4: d_{12}$ damage evolution in the plies

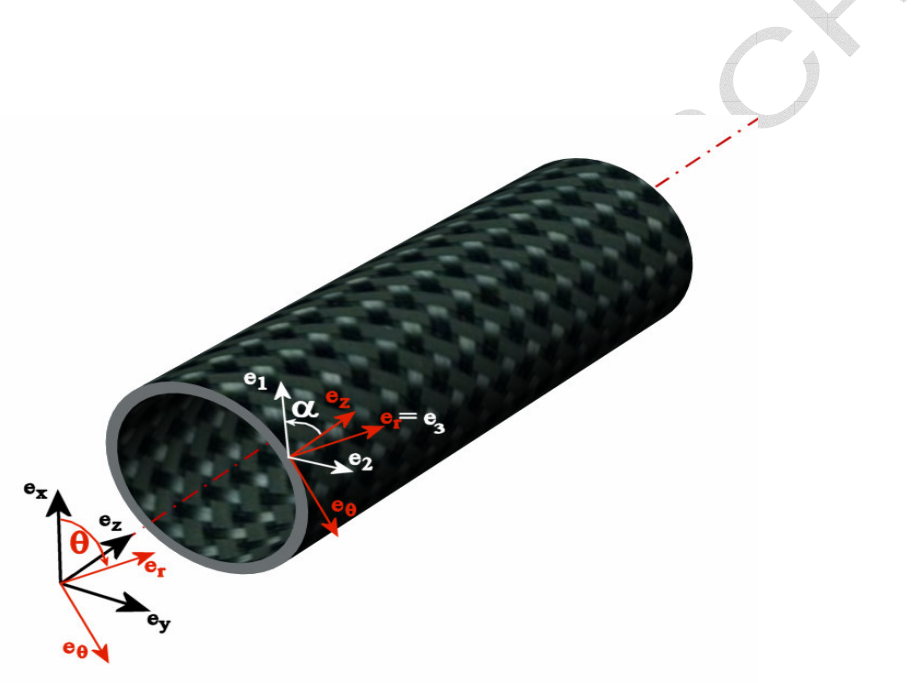

Figure 1 


\section{ACCEPTED MANUSCRIPT}
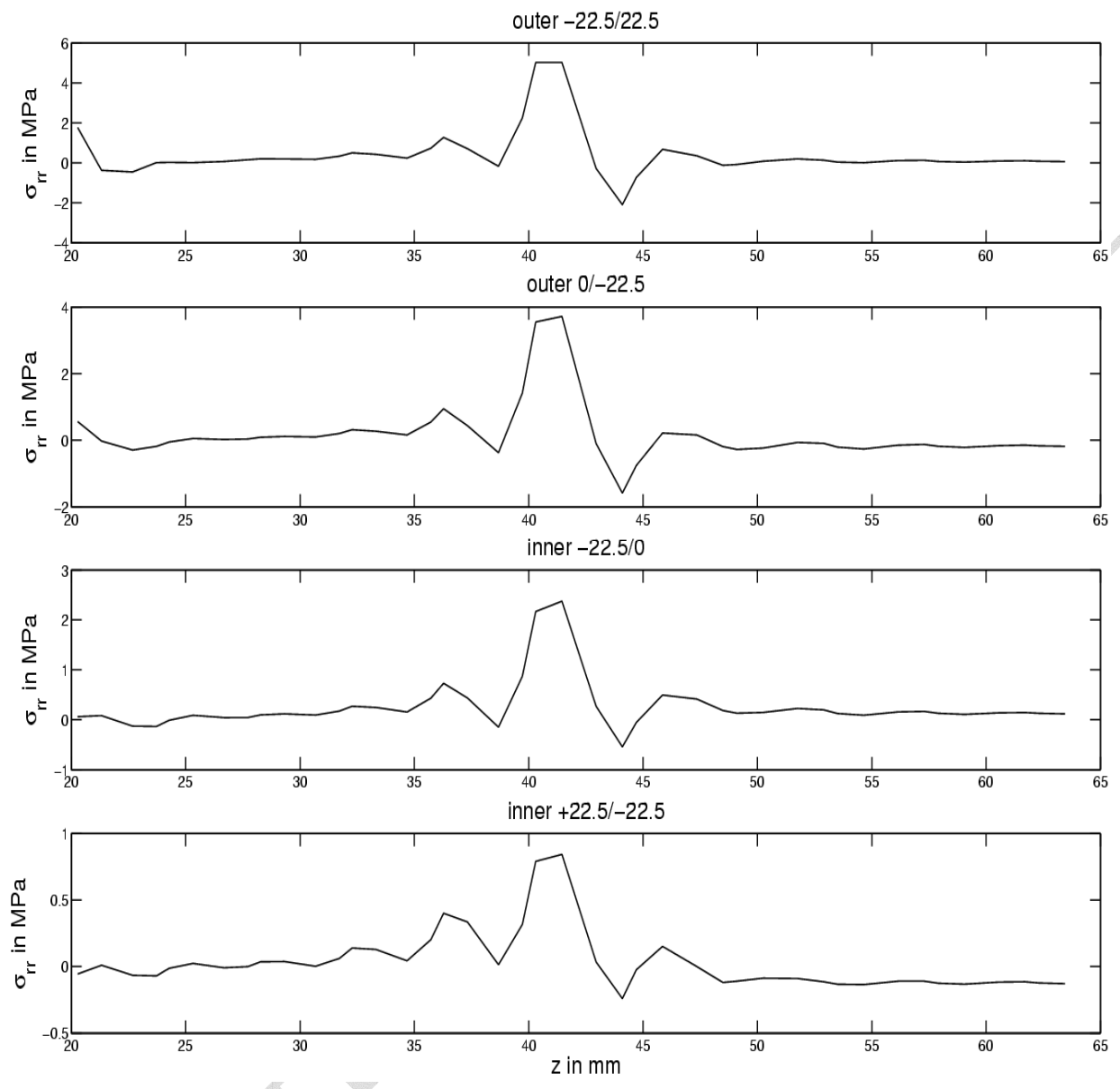

Figure 2 

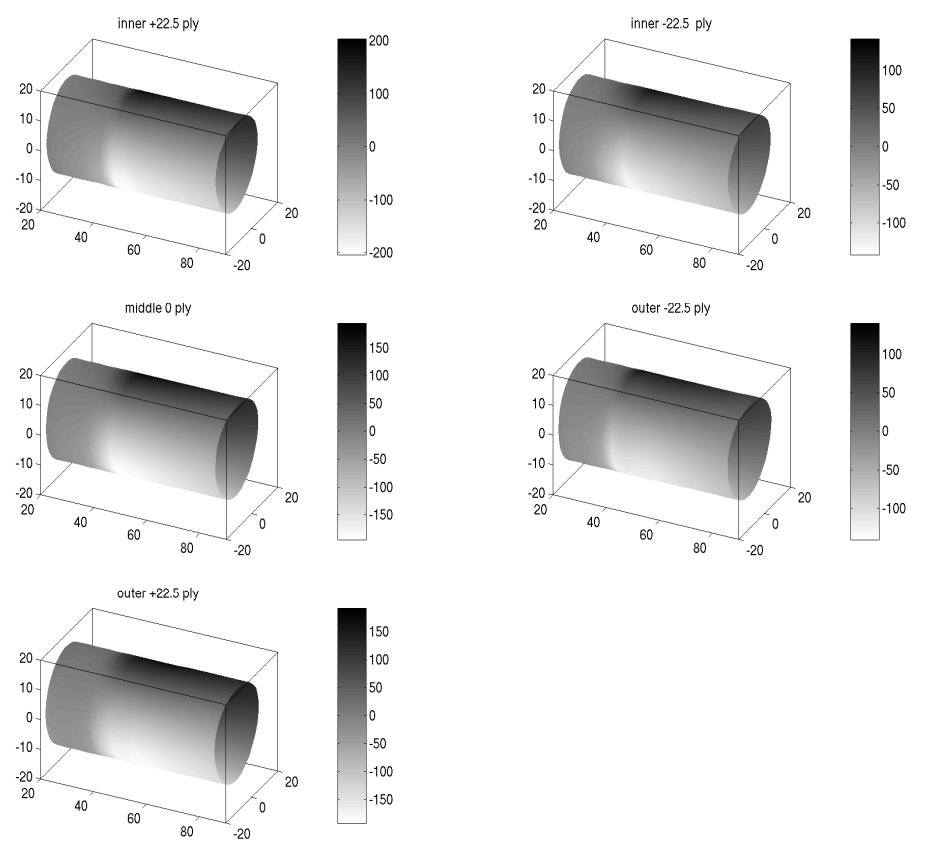

Figure 3 

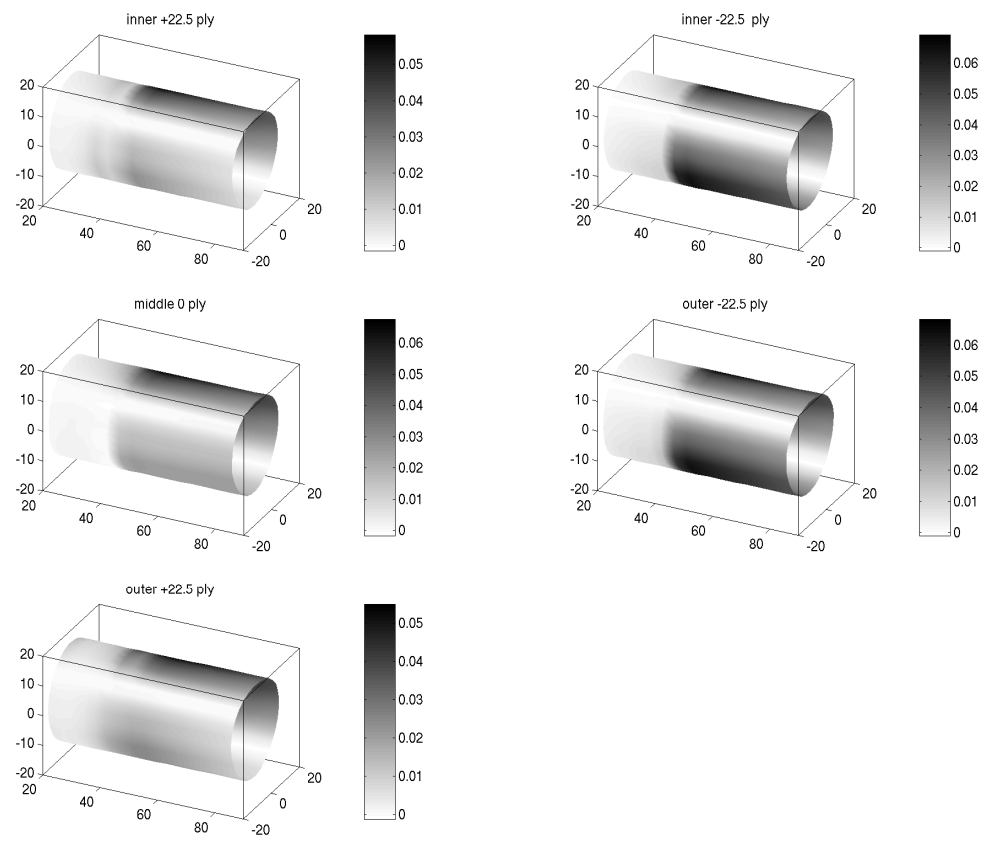

Figure 4 